\title{
Is AIO belly board device advantageous in all rectal cancer patients irradiated in the pelvic area?
}

\author{
Dominika Hempel ${ }^{1,2}$, Joanna Mandrosz ${ }^{3}$, Marek Z. Wojtukiewicz ${ }^{1,4}$, \\ Tomasz Filipowski², Ewa Sierko ${ }^{1,2}$
}

Purpose. To compare the prone position on a flat table vs an "All in one" belly board device (AIO BBD) in rectal cancer patients (RCPs).

Material and methods. Fifteen RCPs scheduled for irradiation were scanned in the two evaluated positions. After tomography, they completed a questionnaire concerning positioning. The dose-volume histograms (DVHs) for the small bowel and bladder were compared for both immobilization methods and setup accuracy was analyzed in electronic portal imaging devices (EPIDs) and X-ray volume imaging (XVI) procedures.

Results. AIO BBD was accepted by the majority of RCPs and provided better DVHs for the small bowel than the prone position on a flat table. The setup reproducibility was within tolerance limit for patients with $\mathrm{BMI} \leq 29 \mathrm{~kg} / \mathrm{m}^{2}$. Patients with obesity regarded AIO BBD as uncomfortable and they presented mean setup shifts out of the tolerance limit in the $Y$ axis $-5.9 \mathrm{~mm}$.

Conclusions. The AIO BBD should be recommended for RCPs, especially for those with BMI $\leq 29 \mathrm{~kg} / \mathrm{m}^{2}$.

NOWOTWORY J Oncol 2017; 67, 6: 342-348

Key words: rectal cancer, AIO belly board device, small bowel exposure, setup shifts

\section{Introduction}

Radiotherapy is an integral part of the radical treatment of locally advanced rectal cancer patients (RCPs) [1]. Unfortunately, pelvic area irradiation may be complicated by acute and/or late gastrointestinal as well as urinary toxicity, which is observed in $2-30 \%$ of RCPs [2-4]. In light of the information that there is an association between irradiated volume of the small bowel and intestinal complications [4-6], many concepts for decreasing bowel exposure to irradiation have been investigated. The amount of small bowel irradiated can be reduced by the use of what is known as a "full bladder protocol" $[7,8]$, the choice of a prone vs supine position of the patient $[6,9,10]$ and the positioning of patients on a belly board device (BBD) [6, 11-18]. BBD implementation leads to an improvement of dose-volume histogram (DVH) in the small bowel in both pre- $[7,8]$ and postoperatively $[3,12]$ irradiated patients undergoing 3D conformal radiotherapy (3D-CRT) or intensity modulated radiotherapy (IMRT) $[9,11,12,19,20]$. Although both the entire bowel area and individual intestinal loops have been delineated by radiation oncologists, the majority of authors agree that single intestinal loop exposure is more predictive for acute and late toxicity than the entire bowel region [5, $14,21,22]$. Of note, the volume of small bowel receiving 15 Gy (V15) and 45 Gy (V45) are the most relevant parameters for predicting toxicity using the normal tissue complication probability (NTCP) model [5, 21-23]. The volume of single loops receiving more than 15 Gy or 45 Gy should be kept under 120-150 cc and $78 \mathrm{cc}$, respectively [5, 21, 22]. Unfortunately there are many types of BBDs commercially available

\footnotetext{
${ }^{1}$ Department of Oncology, Medical University of Białystok, Poland

${ }^{2}$ Department of Radiotherapy, Comprehensive Cancer Center in Białystok, Poland

${ }^{3}$ Radiation Oncology Division, Medical University of Białystok, Poland

${ }^{4}$ Department of Clinical Oncology, Comprehensive Cancer Center in Białystok, Poland
} 
on the market, which impedes comparison of results from different studies. Namely, there are square belly boards with an adjustable size of the octagonal opening and position of its lower border [3, 24], devices with bladder compression [17] or boards with additional hole for testes [18] and, used in our study, an egg-shaped/one-size AIO ("All In One") belly board device.

The aim of the study was to compare subjective (rectal cancer patients preferences) and objective (DVHs and EPID/ $\mathrm{XVI}$ verification) aspects of AIO-based immobilization vs the prone position on a flat table.

\section{Material and methods}

Fifteen consecutive locally advanced RCPs (mean age and body weight were 65 years and $78 \mathrm{~kg}$, respectively) scheduled to receive pre- (short scheme) or postoperative (long scheme) 3D-CRT in the pelvic area were evaluated prospectively. Approval for this study was obtained from the Human Care Committee of the Medical University in Bialystok, Poland. Written informed consent was obtained from the patients. The demographic characteristics of the study group and radiotherapy details are presented in Table I.

\section{Radiotherapy planning and treatment}

A "full bladder" protocol was used in studied patients. They were asked to drink half a litre of water 40 minutes before simulation and delivery of radiotherapy. Each patient was immobilized twice during primary simulation ${ }_{1}$. prone on a flat table with a kneefix under the shins (Fig. 1) and ${ }_{2 .}$ on an AIO belly board device composed of individually selected styrofoam pieces with a special egg-shaped/one-size hole (Fig. 2a) and additional accessories like a kneefix and head bolster (Fig. 2b). Computed tomography (CT) scans were performed in each position. After CTs, patients were asked to fill out by themselves an institution developed questionnaire concerning their opinion about the positionings. The questionnaire contained 8 closed questions and 2 open questions assessing different characteristics of immobilization.

Respiratory motion of the patient's body was determined during the simulation by measurement of shifts in the lateral positioning module in the isocentrum on the $Z$ axis on the patient's skin. Computed tomography scans were taken from the L3-L4 junction to the perineum with $5 \mathrm{~mm}$ slice spacing. The clinical target volumes (CTVs) were defined according to RTOG recommendations on CT scans performed in two positions (with and without AIO BBD) [25] taking care that the size of the treatment fields were similar. The longitudinal extension of the planning target volume (PTV) (8-10 $\mathrm{mm}$ margin encompassing the CTV) were added for both $\mathrm{CT}$ s series. The delineation comprised the following OARs: the bladder, small intestine and heads of femoral bones. Taking into consideration the fact that the volume of the small bowel has two definitions in the lite-
Table I. Characteristics of the studied group — rectal cancer patients treated with pre- or postoperative 3D conformal radiation therapy (RT), $\mathrm{n}=15$

\begin{tabular}{|c|c|}
\hline Characteristics & Value \\
\hline \multicolumn{2}{|l|}{ Age [yr]: } \\
\hline mean & 65 \\
\hline $\min -\max$ & $54-77$ \\
\hline \multicolumn{2}{|l|}{ Sex: } \\
\hline $\mathrm{F}$ & 4 \\
\hline M & 11 \\
\hline \multicolumn{2}{|l|}{ BMI $\left[\mathrm{kg} / \mathrm{m}^{2}\right]:$} \\
\hline$<25$ & 5 \\
\hline $25-29$ & 7 \\
\hline$>29$ & 3 \\
\hline \multicolumn{2}{|l|}{ TNM: } \\
\hline T3N0M0 & 10 \\
\hline T3N1M0 & 2 \\
\hline T3N2M0 & 2 \\
\hline T4NOMO & 1 \\
\hline RT schedule: & 11 \\
\hline $25 \mathrm{~Gy} / 5 \mathrm{~Gy} / 5$ fractions & 4 \\
\hline \multicolumn{2}{|l|}{$50 \mathrm{~Gy} / 2 \mathrm{~Gy} / 25$ fractions } \\
\hline RT: & 11 \\
\hline Preoperative & 4 \\
\hline \multicolumn{2}{|l|}{ Postoperative } \\
\hline \multicolumn{2}{|c|}{ Megavoltage $\mathrm{X}$ photon beam energy: } \\
\hline 6 & 3 \\
\hline 15 & 12 \\
\hline
\end{tabular}

$\mathrm{BMI}$ - body mass index, $\mathrm{F}$ - female, $\mathrm{M}$ - man, $\mathrm{T}$ - tumor, $\mathrm{N}$ - nodes, $\mathrm{M}-$ metastases, Gy - grey

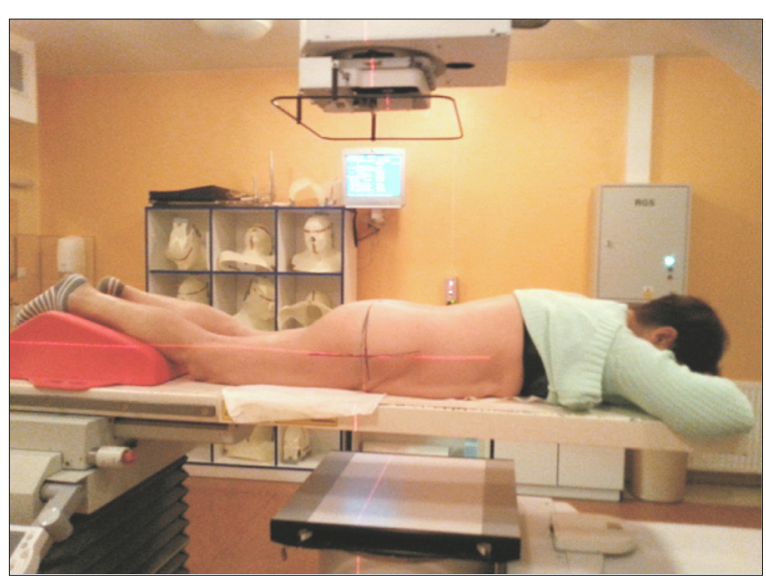

Figure 1. Patient in prone position on simulation coach with kneefix under the shins

rature, both the bowel area referred to as abdominal space (peritoneal cavity) excluding the colon and large vessels as well as single bowel loops were delineated $2 \mathrm{~cm}$ above the PTV (up to the L4-L5 interspace). The analyzed doses in the small bowel and bladder (Table II) were compared for two immobilization methods (the notation V5, V15, V25, etc. was 

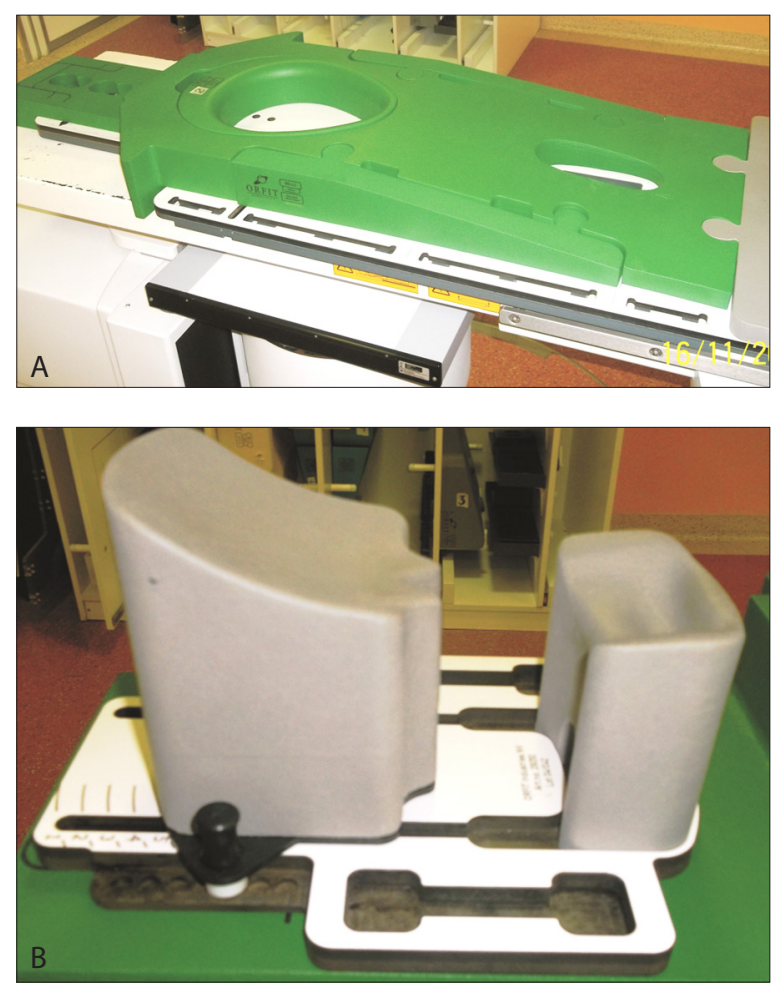

Figure 2. "All in One" belly board device (AIO BBD). AIO in position on simulation coach $(A)$, head bolster $(B)$

used for the volume that receives a maximum dose of 5, 15 or $25 \mathrm{~Gy}$, etc., respectively). All radiation treatment plans met ICRU-62 requirements. Treatment plans assumed to be the most clinically acceptable were carried out ( 14 plans were accepted for patients immobilized on AIO BBD, 1 plan — for patient immobilized in a prone position on flat table).

\section{Setup verification}

EPID ( $0^{\circ}$ and $90^{\circ}$ projections) as well as kV XVI (Elekta, v. 4.2) scans were performed for setup verification (14 patients were finally irradiated on AIO BBD and 1 patient was immobilized in a prone position on a flat table). In accordance with the protocol, IGRT procedures were performed before the 1st, $2 \mathrm{nd}$, 3rd and every 7 th fractions as well as in the case of more than $5 \mathrm{~mm}$ displacement in the pelvic area (long RT-schedule patients) or daily (short RT-schedule

Table II. Analyzed parameters of dose-volume distribution in the small intestine and bladder

\begin{tabular}{ll}
\hline $\begin{array}{l}\text { Small intestine } \\
\text { (bowel area and single loops) }\end{array}$ & Bladder \\
\hline Short radiotherapy (total dose of $25 \mathrm{~Gy})$ & \\
V5, V15, V25 & V15, V25 \\
Long radiotherapy (total dose of $50 \mathrm{~Gy})$ & \\
V5, V15, V25, V30, V45, V50 & V30, V50 \\
\hline
\end{tabular}

* V5 - the volume of the organ which received the maximum dose of $5 \mathrm{~Gy}$ patients). The patient's setup shifts on the $X$ (lateral), $Y$ (longitudinal), and Z (vertical) axes were evaluated.

The data was analyzed statistically using Microsoft Excel and Statistica v. 10 programs. The Spearman's test ranks were chosen for verification of the hypotheses. A confidence level of 0.05 was accepted.

\section{Results \\ Patients' opinions}

The majority of respondents (approx. 70-80\% depending on the question) regarded the AIO BBD as a convenient, stable, safe and/or simple to reproduce positioning method. A similar percentage of the respondents assessed the prone on a flat table position as safe (75\%) but less than half felt stability (30\%) or comfort (40\%) when lying directly on the simulation couch. Finally, $73 \%$ of the respondents would choose the AIO positioning system if they were to decide and only one-fourth the position directly on the table. The patients who indicated the position on a flat table as better explained their choice with the fact that their body was less strained compared with AIO-based immobilization and they felt that their head and hands were in a more comfortable position. For patients who had chosen the AIO system, this immobilization was more stable and comfortable and did not cause any pain or pressure in the ribs or chest which they suffered in the position directly on the simulation couch.

Of particular importance in terms of radiotherapy planning is the fact that $60 \%$ of respondents did not regard any of the positioning methods as unacceptable. However, $13 \%$ $(n=2)$ and $25 \%(n=4)$ of the patients considered the AIO system or the flat on the table position as inappropriate, respectively. The mean weight of the patients who criticized one of the positioning methods differs significantly - patients who disapproved of the AIO BBD weighed a mean 83 $\mathrm{kg}$, while patients dissatisfied with the position directly on a flat table - a mean $63 \mathrm{~kg}$.

\section{Respiratory motion}

The respiratory motion measured in the isocentrum determined during simulation was smaller on the AIO BBD (mean min-max, 2-5 mm), compared with the prone position on a flat table (mean min-max, 5-15 mm)

\section{Small bowel dose-volume distribution}

Mean small bowel volume was significantly greater $(p$ $=0.03$ ) in patients positioned on the AIO BBD than directly on a flat table, calculating for all patients ( 2520 vs 2218 cc for bowel area and 820 vs 651 cc for single loops).

The DVH for the small bowel in preoperative patients setting $(n=11)$ was more favorable on the AIO BBD vs on the flat table position. Small bowel volumes: SB-V5,-V15 and -V25 were smaller by 8,5 and $4 \%$, respectively on the AIO $\mathrm{BBD}$ compared with the prone on a flat table position for 

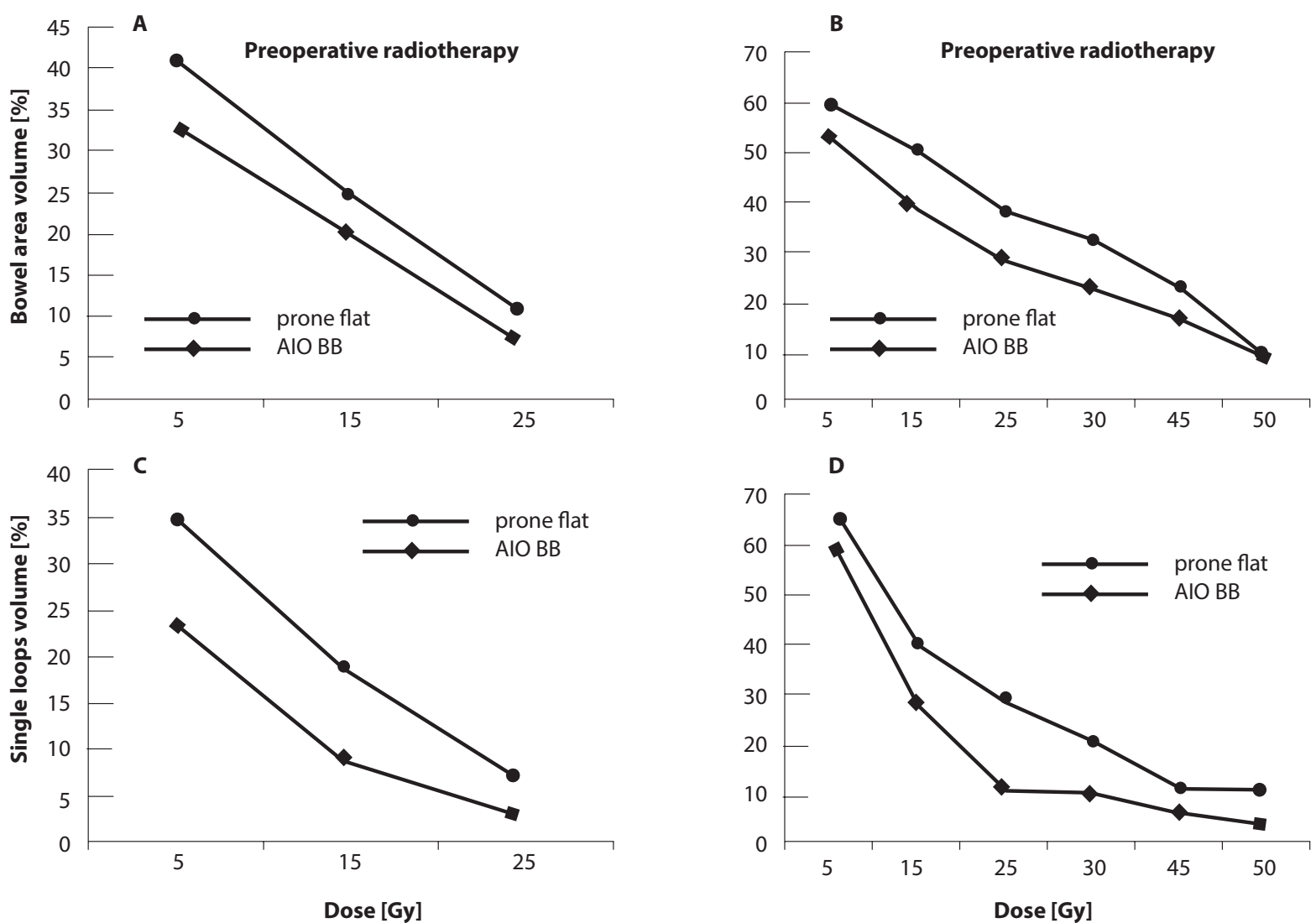

Figure 3. Mean dose-volume histogram for the small bowel (A, B. Bowel area, C, D. Single loops) in preoperatively (total dose 25Gy, $\mathrm{n}=11$ ) and postoperatively (total dose $50 \mathrm{~Gy}, \mathrm{n}=4$ ) irradiated rectal cancer patients immobilized in two treatment positions (prone on a flat table and on an AIO BBD)

the bowel area (Fig. 3A) and by 11, 10 and 4\%, respectively for single loops (Fig. 3C).

The DVH for the small bowel was also better on the AIO BBD than the prone on a flat table position in patients irradiated postoperatively with a dose of $50 \mathrm{~Gy}$ : SB-V5, -V15, -V25, -V30 and V45 was reduced by $6,10,8,8$ and $5 \%$ for the bowel area and by $6,12,18,11$ and $4 \%$ for single loops, respectively (Fig. $3 \mathrm{~B}, \mathrm{D}$ ).

The largest absolute reduction of the irradiated volume of the small bowel was predominantly seen in the low and intermediate dose areas of the treatment volume - V5V15 for short radiotherapy and V15-V30 for a long scheme $(p<0.05)$. The volume reduction does not correlate with gender, age, weight and sequence of radiation treatment vs surgery. There was no significant difference in V25 for short and V45-50 for long radiotherapy between the two analyzed positions ( $p>0.05$ ).

The unfavourable DVH for small bowel was observed on the AIO BBD in a patient with BMI calculated as more than $29 \mathrm{~kg} / \mathrm{m}^{2}$ (Fig. 4). This patient assessed the AIO BBD as uncomfortable and claimed to have difficulty to fit their belly tissues into the opening. Taking into consideration patient's opinion and the DVH, this individual patient was irradiated in the prone on a flat table position without the BBD.
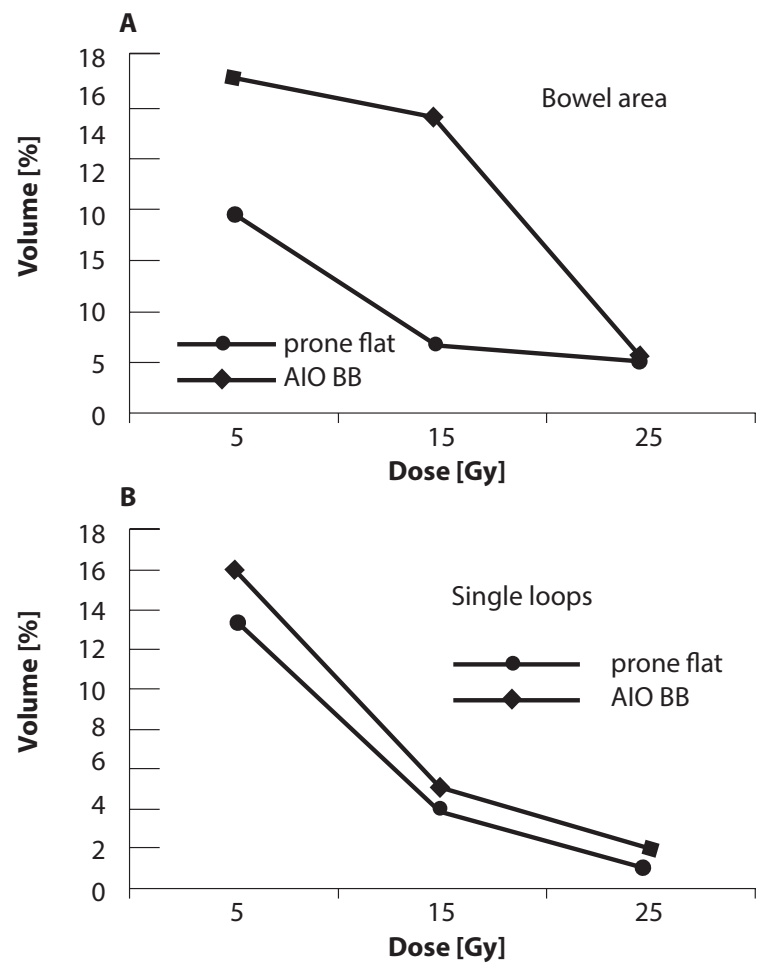

Figure 4. Dose-volume histogram for the small bowel (A. Bowel area, B. Single loops) in preoperatively (total dose $25 \mathrm{~Gy}$ ) irradiated rectal cancer patients with $\mathrm{BMI}>29 \mathrm{~kg} / \mathrm{m}^{2}$ immobilized in two treatment positions (prone on flat table and on an AIO BBD) 


\section{Bladder dose-volume distribution}

The volume of the bladder on the AIO-based and prone on a flat table positions was similar (234 vs 241 cc, respectively, $\mathrm{p}>0.05)$. The DVH for the bladder was not significantly different between two positioning methods $(p>0.05)$ in preoperative and postoperative patient settings in all analyzed parameters (Fig. 5 A, B).

\section{EPID and $k V X V I$ set-up discrepancies}

Immobilization on the AIO BBD provided excellent reproducibility of patient positioning. The setup errors detected in EPID and kV XVI scans did not exceed the tolerance limit approved for the pelvic area $(\leq 5 \mathrm{~mm})$. EPID analysis showed the greatest mean setup shifts on the $X$ axis $(2.7 \mathrm{~mm}$, $S D=1.5)$. Lower mean setup errors were reported in the $Y$ ( $2.3 \mathrm{~mm}, \mathrm{SD}=1.66)$ and $\mathrm{Z}(1.1 \mathrm{~mm}, \mathrm{SD}=0.84)$ directions. Setup displacement assessed in XVI scans were $3.7 \mathrm{~mm}$, $\mathrm{SD}=3.0 ; 2.6 \mathrm{~mm}, \mathrm{SD}=2.2$ and $2.6 \mathrm{~mm}, \mathrm{SD}=2.3$ on the $\mathrm{Y}, \mathrm{X}$ and $Z$ axes, respectively.

The detailed analysis showed that in patients with BMI $\leq 29 \mathrm{~kg} / \mathrm{m}^{2}$ the XVI verifications were within limits on all three axes. However, in obese patients (BMI $\left.>29 \mathrm{~kg} / \mathrm{m}^{2}\right)$, the setup displacement exceeded $5 \mathrm{~mm}$ on the $\mathrm{Y}$ axis (mean value $0.59 \mathrm{~mm}$, min-max $0.1-13 \mathrm{~mm}$ ) (Fig. 6).
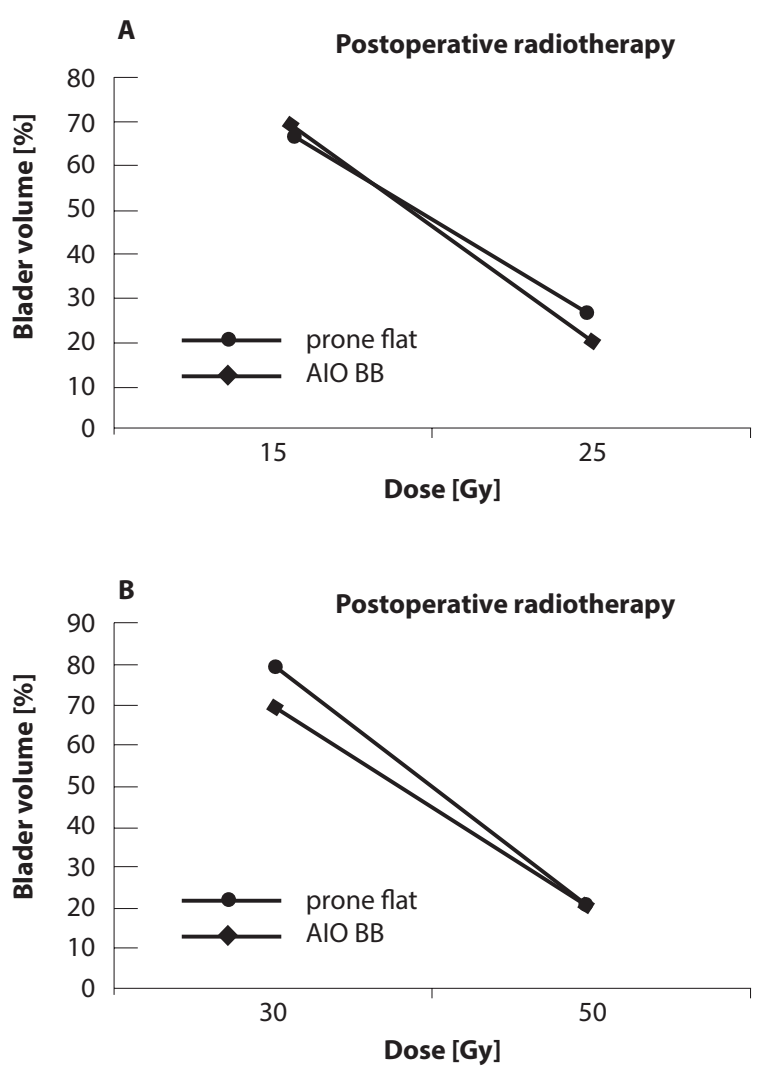

Figure 5. Mean dose-volume histogram for the bladder in preoperatively (A), total dose $25 \mathrm{~Gy}, \mathrm{n}=11$ and postoperatively (B), total dose $50 \mathrm{~Gy}, \mathrm{n}=4$ irradiated rectal cancer patients immobilized in two treatment positions (prone on flat table and on an AIO BBD)

\section{Discussion}

To the best of our knowledge, this is the first study which comprehensively compares patient preferences, dose distribution in organs at risk, and setup errors of the AIO BBD vs the prone position on a flat table in rectal cancer patients. The majority of patients assessed the AIO BBD as safe and comfortable and would choose it as a method of immobilization. The reduced respiratory motion of the abdomen was an additional advantage of the AIO BBD. Our findings have also shown that the AIO BBD provides low and intermediate dose volume advantages in the small bowel (for the bowel area and single loops) compared with the prone position on a flat table, both in patients irradiated pre- as well as postoperatively. The lack of effect for high dose regions was probably due to the overlap between PTV and the bowel area or single loops. Additionally, analysis of setup shifts indicated that reproducibility is excellent and within tolerance limits for patients stabilized on the AIO BBD. These results are consistent with those reported in the literature regarding various commercially available $B B D s[3,6-8,13$, $14,16-18,24]$ and confirm the conclusion that AIO BBD should be recommended as a method of immobilization in the majority of RCPs. However, some observations associated with patient weight are concerning and call for caution before recommending this device for all patients. It seems that patients with $\mathrm{BMI}>29 \mathrm{~kg} / \mathrm{m}^{2}$ may have difficulties with adapting to the one-size/egg-shaped opening found a relatively short distance from the head bolster. Although there was no significant correlation between dose-volume reduction in the small bowel and patient weight on the AIO $B B D$, the DVH for the small bowel for obese patients in this immobilization was worse compared with prone on a flat table. The V15 in the bowel area and single loops was as high as 237.8 and $41 \mathrm{cc}$ on the AIO BBD and only 45.57 and 26.04 cc in the prone on a flat table position, respectively. Moreover, the setup shifts in two other patients with $\mathrm{BMI}>29$ $\mathrm{kg} / \mathrm{m}^{2}$ irradiated, despite their negative opinion, on an AIO BBD due to the small advantage in DVHs for the small bowel, exceeded the tolerance limit on the $Y$ axis. The maximum

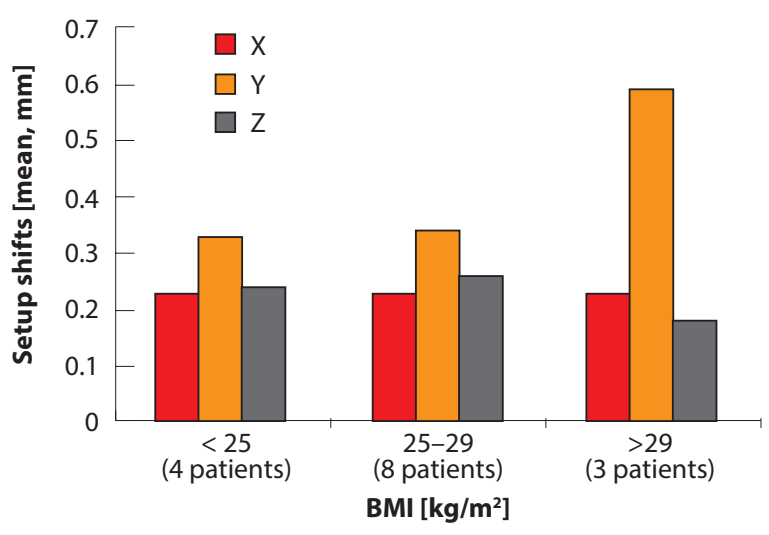

Figure 6. Mean setup shifts in $\mathrm{X}, \mathrm{Y}, \mathrm{Z}$ axes according to body mass index (BMI) in rectal cancer patients irradiated on an AIO BBD $(n=14)$ 
value of setup displacement reached $13 \mathrm{~mm}$. The observed setup errors indicate the need to adjust the immobilization method to patient weight. The clinical importance of patient immobilization in regard to gastrointestinal and urinary toxicity will be detected by the prospective phase II clinical trial (NCT01142713) titled"The Impact of Patient Positioning and Use of Belly Board on Small Bowel and Urinary Bladder Volume Irradiated in Patients Receiving Radiotherapy for Rectal Cancer" (www.clinicaltrials.gov).

It is difficult to relate our observations to other studies because there are no investigations dedicated to patients' opinions about AIO BBD nor dose-volume distribution in the small bowel, and positioning verification for this particular immobilization has been so far only explored. Only Nijkamp [14] mentions, also in the discussion, that for some volunteers the small compression verge of BBD may be considered uncomfortable. Rajeev et al. [15] reports in their discussion, not in the results section, that body weight was found to be a factor that shows a trend toward more daily patient set up variations in the prone on a belly board vs the supine position. The variations in the $X, Y$ and $Z$ directions were greater in two patients with bodyweight $>100 \mathrm{~kg}$. The correlation between BMI of the patients and setup discrepancies were described in the literature for gynaecological or abdominal malignancies settings [26-28]. Additionally, Czuchraniuk et al. [29] reported an influence of muscle strain on setup errors in patients irradiated in the pelvic area, which may be the key problem for obese patients immobilized on an egg-shaped/one-size AIO BBD (they reported a forced, strained position of the body on this device). It seems that belly board-based positioning in rectal cancer patients requires an IGRT procedure every day to prevent missing the planned planning target volume [30].

What is interesting in the current analysis, the volumes of the bowel area and single loops were greater in AIO BBD compared with the prone on a flat table position. This finding is in conflict with studies assessing other types of BBDs $[3,15]$. The possible explanation is that BBDs are expected to reduce the volume of the small bowel within the pelvis [3]. In our study, the small bowel volume was delineated 2 $\mathrm{cm}$ above PTV (at least L4-L5 junction) to present low dose regions on DVHs. Some part of abdominal cavity (which is greater in AIO BBD due to the opening in styrofoam than in position on flat table), outside of the PTV, was included. The other authors have used the lower upper edge of the delineation, as local recurrences occurred mainly in the lower pelvis, below the S1-S2 interspace [14, 15, 22, 31, 32]. However, our findings definitely showed that dose distribution in the absolute volume of the small bowel was advantageous for AIO BBD. The newest international guidelines on delineation in rectal cancer [33] indicate that in the case of cT3, cN0 tumors without invasion of the mesorectal facia, the upper border of the radiotherapy field can be lowered to the cranial border of the mesorectum, corresponding with the bifurcation of the superior rectal artery, which reduces the volume of the small bowel within irradiated fields.

\section{Conclusions}

Despite numerous limitations of the study (small number of patients with obesity, no clinical data about toxicity, single-institution investigation), it provides a good estimate of the value of AIO BBD in patients with $B M I \leq 29 \mathrm{~kg} / \mathrm{m}^{2}$. The present findings showed that for these patients, AIO BBD provides better dose-volume distribution in the small bowel combined with excellent reproducibility compared with the prone on a flat table position. Additionally, patients assessed the AIO BBD as convenient and stable. However, patients with $\mathrm{BMI}>29 \mathrm{~kg} / \mathrm{m}^{2}$ should be positioned with greater care. Immobilization on AIO BBD may be uncomfortable for these patients, cause worse dose-volume distribution in the small bowel and/or result in unacceptable setup shifts. Larger studies are required to improve the statistical power of the analyzed variations.

\section{Conflict of interest: none declared}

\section{Ewa Sierko, MD, PhD}

Medical University of Białystok

Department of Oncology

ul. Kilińskiego 1

15-089 Białystok, Poland

e-mail:ewa.sierko@iq.pl

\section{Received: 13 Oct 2017}

Accepted: 22 Jan 2018

\section{References}

1. Wu SG, Zhang WW, Sun JY et al. Preoperative radiotherapy improves survival in rectal signet-ring cell carcinoma - a population-based study. Radiat Oncol 2017; 12: 141.

2. Kavanagh BD, Pan CC, Dawson LA et al. Radiation dose-volume effects in the stomach and small bowel. Int J Radiat Oncol Biol Phys 2010; 76 (3 Suppl): S101-107.

3. Koelbl O, Vordermark D, Flentje M. The relationship between belly board position and patient anatomy and its influence on dose-volume histogram of small bowel for postoperative radiotherapy of rectal cancer. Radiother Oncol 2003; 67: 345-349.

4. Tho LM, Glegg M, Paterson J et al. Acute small bowel toxicity and preoperative chemoradiotherapy for rectal cancer: investigating dose-volume relationships and role for inverse planning. Int J Radiat Oncol Biol Phys 2006; 66: 505-513.

5. Gunnlaugsson A, Kjellén E, Nilsson P et al. Dose-volume relationships between enteritis and irradiated bowel volumes during 5 -fluorouracil and oxaliplatin based chemoradiotherapy in locally advanced rectal cancer. Acta Oncol 2007; 46: 937-944.

6. Wang, JF, Li H, Xiong $\mathrm{H}$ et al. Influence of position and radiation technique on organs at risk in radiotherapy of rectal cancer. J Huazhong Univ Sci Technolog Med Sci 2016; 36: 741-746.

7. Kim TH, Chie EK, Kim DY et al. Comparison of the belly board device method and the distended bladder method for reducing irradiated small bowel volumes in preoperative radiotherapy of rectal cancer patients. Int J Radiat Oncol Biol Phys 2005; 62: 769-775.

8. Kim TH, Kim DY, Cho KH et al. Comparative analysis of the effects of belly board and bladder distension in postoperative radiotherapy of rectal cancer patients. Strahlenther Onkol 2005; 181: 601-605.

9. White R, Foroudi F, Sia J et al. Reduced dose to small bowel with the prone position and a belly board versus the supine position in neoa- 
djuvant 3D conformal radiotherapy for rectal adenocarcinoma. J Med Radiat Sci 2017; 64: 120-124.

10. Drzymala M, Hawkins MA, Henrys AJ et al. The effect of treatment position, prone or supine, on dose-volume histograms for pelvic radiotherapy in patients with rectal cancer. Br J Radio/ 2009; 82: 321-327.

11. Estabrook NC, Bartlett GK, Compton JJ et al. Role of belly board device in the age of intensity modulated radiotherapy for pelvic irradiation. Med Dosim 2016; 41: 300-304.

12. Kim JY, Kim DY, Kim TH et al. Intensity-modulated radiotherapy with a belly board for rectal cancer. Int J Colorectal Dis 2007; 22: 373-379.

13. Allal AS, Bischof $S$, Nouet P. Impact of the "belly board" device on treatment reproducibility in preoperative radiotherapy for rectal cancer. Strahlenther Onkol 2002; 178: 259-262.

14. Nijkamp J, Doodeman B, Marijnen C et al. Bowel exposure in rectal cancer IMRT using prone, supine, or a belly board. Radiother Oncol 2012; 102: 22-29.

15. Rajeev KR, Menon SS, Beena $\mathrm{K}$ et al. A comparative study of set up variations and bowel volumes in supine versus prone positions of patients treated with external beam radiation for carcinoma rectum. Cancer Res Ther 2014; 10: 937-941.

16. Chung $\mathrm{Y}$, Yoon HI, Keum KC et al. Effect of belly board with bladder compression device on small bowel displacement from the radiotherapy field for rectal cancer. Onkologie 2013; 36: 241-246.

17. Wiesendager-Wittmer EM, Sijtsema NM, Muijs CT et al. Systematic review of the role of a belly board device in radiotherapy delivery in patients with pelvic malignancies. Radiother Oncol 2012; 102: 325-334.

18. Vorwerk H, Hermann RM, Christiansen Het al. A special device (double-hole belly board) and optimal radiation technique to reduce testicular radiation exposure in radiotherapy of rectal cancer. Radiother Oncol 2007; 84: 320-327.

19. Wang $Y$, Xia X, Zhe H et al. Is belly board still needed in IMRT for rectal cancer? The change of bladder volume affects the determination. Int J Radiat Oncol Biol Phys 2012; 84 Suppl: S343.

20. Samuelian JM, Callister MD, Ashman JB et al. Reduced acute bowel toxicity in patients treated with intensity-modulated radiotherapy for rectal cancer. Int J Radiat Oncol Biol Phys 2012; 82: 1981-1987.

21. Robertson JM, Lockman D, Yan D et al. The dose-volume relationship of small bowel irradiation and acute grade 3 diarrhea during chemoradiotherapy for rectal cancer. Int J Radiat Oncol Biol Phys 2008; 70: 413-418.

22. Baglan KL, Frazier RC, Yan D et al.The dose-volume relationship of acute small bowel toxicity from concurrent 5-FU-based chemotherapy and radiation therapy for rectal cancer. Int J Radiat Oncol Biol Phys 2002; 52: $176-183$.

23. Roeske JC, Bonta D, Mell LK et al. A dosimetric analysis of acute gastrointestinal toxicity in women receiving intensity-modulated whole-pelvic radiation therapy. Radiother Oncol 2003; 69: 201-207.

24. Cranmer-Sargison G, Kundapur V, Ternes S et al. Using kV- $\mathrm{kV}$ and CBCT imaging to evaluate rectal patient position when treated prone on a newly available belly board. Med Dosim 2012; 37: 117-121.

25. https://www.rtog.org/CoreLab/ContouringAtlases.aspx.

26. Kim H, Beriwal S, Huq MS et al. Evaluation of set-up uncertainties with daily kilovoltage image guidance in external beam radiation therapy for gynaecological cancers. Clin Oncol (R Coll Radiol) 2012; 24: e39-45.

27. Ziółkowski Sz, Biedka M, Żmuda E et al. Practical issues in radiotherapy of obese patients. Engineer and Medical Physic 2014; 3: 111-114.

28. Choi M, Fuller CD, Wang SJ et al. Effect of body mass index on shifts in ultrasound-based image-guided intensity-modulated radiation therapy for abdominal malignancies. Radiother Oncol 2009; 91: 114-119.

29. Czuchraniuk P, Bujko K, Kukołowicz P et al. Ocena wpływu napięcia mięśni na obszar napromienianych tkanek regionu miednicy. Reports of Practical Oncology \& Radiotherapy 2004; 9 (Suppl2): 249.

30. Miyamoto J, Michaud AL, Harandi NK et al. The role of image-guided radiotherapy in the treatment of anorectal cancer using prone belly-board positioning. Anticancer Res 2016; 36: 3013-3017.

31. Syk $E$, Torkzad MR, Blomqvist $L$ et al. Local recurrence in rectal cancer anatomic localization and effect on radiation target. Int $J$ Radiat Oncol Biol Phys 2008; 72: 658-664

32. Nijkamp J, Kusters M, Beets-Tan R et al. Three-dimensional analysis of recurrence patterns in rectal cancer: the cranial border in the hypofractionated preoperative radiotherapy can be lowered. Int J Radiat Oncol Biol Phys 2011; 80: 103-110.

33. Valentini V, Gambacorta MA, Barbaro B et al. International consensus guidelines on Clinical Target Volume delineation in rectal cancer. Radiotherapy Oncol 2016; 120: 195-201. 